\title{
Avaliação da política de apoio ao estudante desenvolvida pela UNIRIO: o Projeto de Bolsa Permanência
}

Jair Cláudio Franco de Araújo*

Ligia Silva Leite**

\section{Resumo}

O presente estudo teve como objetivo avaliar a adequação da Bolsa Permanência concedida pela Universidade Federal do Estado do Rio de Janeiro (UNIRIO) aos estudantes oriundos de segmentos socioeconômicos menos favorecidos, considerando as especificidades da Universidade e dos estudantes contemplados com a referida bolsa. Foi desenvolvido numa abordagem responsiva uma vez que o aprofundamento do conhecimento dos elementos da cultura institucional é essencial para a compreensão da ação avaliada e pretendeu refletir os valores e perspectivas dos estudantes e profissionais envolvidos com a Bolsa Permanência. A coleta de dados foi realizada com a utilização de um questionário e um roteiro de entrevistas. Foram obtidos dados de 71 estudantes bolsistas matriculados em 19 diferentes cursos de Graduação e realizadas duas entrevistas com o Departamento de Assuntos Comunitários e Estudantis (DACE). A análise dos dados foi realizada por meio de estatística descritiva. Foi realizado exame de coerência dos resultados identificando convergências e possíveis divergências entre a visão dos estudantes bolsistas e a visão proposta pela administração da universidade. Os resultados encontrados sinalizam para a possibilidade de a Bolsa Permanência atingir os propósitos para os quais foi criada.

Palavras-chave: Avaliação. educação superior. Ações afirmativas no Ensino Superior.

Mestre em Avaliação, Fundação Cesgranrio. Especialista em Processo Justiça e Cidadania. Bacharel em Direito. Técnico em Contabilidade. Diretor de Orçamento da Universidade Federal do Estado do Rio de Janeiro UNIRIO. E-mail: jcfranco@unirio.br

** Pós-doutorado em Educação. Professora Adjunta do Mestrado Profissional em Avaliação da Fundação Cesgranrio e da Faculdade de Educação da UERJ. E-mail: ligialeite@terra.com.br 


\section{Contexto}

A Constituição brasileira estabelece que a educação, direito de todos e dever do Estado e da família, será promovida e incentivada com a colaboração da sociedade, visando ao pleno desenvolvimento da pessoa, seu preparo para o exercício da cidadania e sua qualificação para o trabalho. Estabelece ainda que o ensino será ministrado com base no princípio de igualdade de condições para o acesso e permanência na escola (BRASIL, 1988).

Nenhum país pode aspirar a ser desenvolvido e independente sem um forte sistema de educação superior. Em um mundo em que o conhecimento sobrepuja os recursos materiais como fator de desenvolvimento humano, a importância da educação superior e de suas instituições é cada vez maior. Para que estas possam desempenhar sua missão educacional, institucional e social, o apoio público é decisivo (BRASIL, 2001). "A temática envolvendo inclusão social tem sido foco de discussões de diferentes nuanças no cenário educacional brasileiro" (SANTANA, 2010). Assim, programas de governo foram criados com o objetivo de propiciar condições para a ampliação do acesso e permanência na educação superior, em nível de graduação e combater as desigualdades sociais e regionais, bem como ampliar a democratização das condições de acesso e permanência dos jovens no Ensino Superior público federal por meio de ações de assistência estudantil. Merece destaque (a) o Programa de Apoio a Planos de Reestruturação e Expansão das Universidades Federais (REUNI) (BRASIL, 2007a) instituído com o objetivo de criar condições para a ampliação do acesso e permanência na educação superior, no nível de graduação, pelo melhor aproveitamento da estrutura física e de recursos humanos existentes nas universidades federais, e (b) o Programa Nacional de Assistência Estudantil (PNAES) instituído com a finalidade de ampliar as condições de permanência dos jovens na educação superior pública federal (BRASIL, 2007b, 2010).

Seguindo as diretrizes dos programas de governo e em vista das atuais diferenças sociais, a Universidade Federal do Estado do Rio de Janeiro (UNIRIO) participa do esforço para ampliar as possibilidades de acesso à universidade para os estudantes pertencentes aos segmentos sociais que historicamente foram pouco representados no ambiente universitário (UNIRIO, [2006a]) considerando ainda que "o acesso à educação formal era limitado e a população com menos recursos estava praticamente excluída do sistema" (CASTRO, 2009). Desta forma, a 
UNIRIO enfrenta o desafio de viabilizar a igualdade de oportunidades, contribuir para a melhoria do desempenho acadêmico e agir, preventivamente, nas situações de repetência e evasão decorrentes da insuficiência de condições financeiras do seu corpo discente. Para tanto, desenvolve diversas ações de assistência estudantil com o objetivo de impulsionar e tentar nivelar as chances de todos terem uma melhor formação acadêmica e profissional, considerando que as políticas de inclusão devem não somente propiciar a permanência de estudantes em risco social, mas também garantir a excelência de sua formação acadêmica.

As ações de assistência estudantil na UNIRIO tiveram seu início marcante com a criação, em 2005 (UNIRIO 2005), da Bolsa Permanência, com o objetivo de promover a inserção de alunos de graduação, oriundos de segmentos socioeconômicos menos favorecidos, em atividades que visem à participação plena na vida universitária, tendo como pressuposto a igualdade de oportunidades de permanência com vistas à qualidade da formação acadêmica (UNIRIO, 2006d).

Sendo a UNIRIO uma Instituição Federal de Ensino Superior, ela é contemplada anualmente no Orçamento Geral da União. Desta forma, os recursos públicos representam sua principal fonte de financiamento. Assim, as ações desenvolvidas pela Universidade devem, naturalmente, ser avaliadas. Por outro lado, existe o desejo institucional de avaliar suas práticas de assistência estudantil de modo a verificar o alcance dos objetivos e a qualidade dos resultados dessas ações na vida dos estudantes para os quais elas se destinam. Assim, transcorridos cinco anos da criação da política de Bolsa Permanência na UNIRIO e considerando que esta política ainda não foi formalmente avaliada, a realização de uma avaliação formal se torna necessária. Por isso, decidiu-se desenvolver um estudo com o objetivo de avaliar a Bolsa Permanência desenvolvida pela UNIRIO e sua adequação às necessidades dos estudantes oriundos de segmentos socioeconômicos menos favorecidos, considerando as especificidades da Universidade e dos estudantes contemplados com a referida bolsa. Desta forma, o autor pretendeu contribuir para o aprimoramento das ações de assistência estudantil desenvolvidas pela instituição.

\section{A Unirio e a Assistência Estudantil}

A UNIRIO é uma Fundação de Direito Público integrante do sistema federal de Ensino Superior, originária da Federação das Escolas Isoladas do Estado da Guanabara (FEFIEG), criada em 1969, quando foram reunidos estabelecimentos 
isolados de Ensino Superior vinculados, anteriormente, aos Ministérios do Trabalho, Comércio e Indústria; Ministério da Saúde e Ministério da Educação e Cultura. Em 1975, com a fusão dos Estados da Guanabara e do Rio de Janeiro, passou a denominar-se Federação das Escolas Federais Isoladas do Estado do Rio de Janeiro (FEFIERJ).

Em 1979, surgiu a UNIRIO criada pela Lei Federal $n^{\circ} 6.655$ (BRASIL, 1979). Era um momento importante na conjuntura política nacional. Mesmo ainda exercendo forte influência, o governo militar não mais detinha o poder anterior. A sociedade civil estava se reorganizando, iniciando um movimento de democratização com forte influência na comunidade universitária. Assim, a UNIRIO nasceu em um momento histórico de redemocratização da sociedade brasileira (UNIRIO, 2006b).

A abertura política no país, na década de 80 , gerou, também, a abertura política nas universidades. Os movimentos docente, técnico-administrativo e estudantil se fortaleceram. A década de 90 iniciou-se com muitas incertezas e indefinições, especialmente sobre o destino das universidades. Naquele momento, não havia certeza sobre o redirecionamento da política universitária que o novo governo iria imprimir. A perspectiva gerada era a de uma política educacional pautada nos princípios neoliberais.

Nesse contexto, a UNIRIO é uma universidade que busca firmar a sua identidade, que procura caminhos para a sua efetiva democratização, que se lança ao desafio de ultrapassar as barreiras fincadas pela conjuntura política nacional. É real o seu desejo de avançar nas esferas acadêmica e administrativa. Sua comunidade, que agrega docentes, discentes e técnico-administrativos, está envolvida no contínuo processo de construção coletiva de uma universidade que tem clareza sobre a sua importância na busca de caminhos para a transformação social de que a população brasileira necessita com urgência (UNIRIO, 2006b).

Tendo como base uma perspectiva de sociedade mais justa, igualitária, com maiores perspectivas de inclusão social e com possibilidade de transformação da realidade, a UNIRIO entende que a educação superior brasileira necessita ser amplamente analisada com o propósito de encontrar soluções inovadoras que permitam superar dificuldades a partir de questionamentos sobre a realidade. É preciso perceber caminhos capazes de contribuir para a construção de uma 
universidade mais próxima da realidade social, menos fechada e excludente. Assim, os processos de democratização do acesso à educação superior e de inclusão social precisam ser privilegiados (UNIRIO, 2006c). Portanto, tornase necessária a adoção de políticas de inclusão que permitam a permanência de estudantes em risco social e, ao mesmo tempo, garantam a excelência de sua formação acadêmica. Vale ressaltar que a efetivação de uma política de assistência aos estudantes não deve se restringir apenas ao atendimento de necessidades básicas referentes à subsistência. Urge o fortalecimento de uma formação ética, humanista e crítica, condição imprescindível para sua inserção nas transformações sociais desejáveis.

Nesse contexto, a política definida para os Assuntos Estudantis da UNIRIO, sempre mediada pela escuta e diálogo, está voltada para oferecer suporte aos discentes (UNIRIO, [2006a]). A partir desse princípio, fazem parte das ações de assistência estudantil da UNIRIO, dentre outros, os seguintes projetos: Bolsa Permanência, Transporte Intercampi, Auxílio Alimentação e Auxílio Moradia.

\subsection{A Bolsa Permanência}

A Bolsa Permanência é destinada aos estudantes de graduação da UNIRIO em situação de vulnerabilidade social, e tem como principal objetivo possibilitar aos discentes o desenvolvimento de seus estudos, tendo como pressuposto a igualdade de oportunidades, com vistas à sua qualificação acadêmica. O seu gerenciamento é realizado pelo Departamento de Assuntos Comunitários e Estudantis (DACE) vinculado diretamente ao Gabinete do Reitor. É concedida sob a forma de auxílio financeiro pago diretamente ao estudante. Os estudantes contemplados com a bolsa são inseridos em atividades acadêmicas e administrativas desenvolvidas pela universidade, com carga horária semanal de 12 horas.

A chamada para seleção de bolsistas é feita anualmente por meio de edital divulgado no âmbito da universidade; e a bolsa tem duração de 12 meses, podendo ser renovada por igual período.

As solicitações de bolsista permanência devem ser encaminhadas ao DACE pelas Direções dos Cursos, Institutos, Unidades ou Setores da UNIRIO, contendo justificativa fundamentada do setor, indicação do supervisor e Plano de Atividades contendo o rol de tarefas a serem desenvolvidas por cada estudante candidato à Bolsa 
Permanência. São vedados Planos de Trabalho Administrativos que impliquem em contato dos Bolsistas com todos os processos de avaliação discente e alimentação de dados de quaisquer sistemas acadêmicos no âmbito da Graduação e da PósGraduação, e atividades não condizentes com o desenvolvimento acadêmico.

A seleção dos estudantes obedece a critérios socioeconômicos e é realizada pelo DACE que também procede a gestão administrativa dos bolsistas.

As atividades dos bolsistas são supervisionadas por docente ou técnicoadministrativo da UNIRIO com a atribuição de acompanhar, orientar e avaliar os bolsistas apoiando-os no cumprimento do Plano de Atividades previamente aprovado e sem prejuízo das atividades acadêmicas. Os supervisores devem ainda manter arquivo sobre os bolsistas, participar das reuniões do DACE, quando convocados, encaminhar a este Departamento, semestralmente, a avaliação de desempenho dos bolsistas e manter atualizada a frequência dos mesmos.

Os estudantes candidatos ao Programa de Bolsa Permanência devem estar regularmente matriculados e frequentando curso de graduação da universidade, dispor de 12 horas semanais para desempenho das tarefas propostas no Plano de Atividade, não possuir vínculo empregatício de qualquer espécie ou receber bolsa de outra modalidade na UNIRIO, ou outro órgão financiador, e atender às especificações da análise socioeconômica que tem por objetivo verificar a condição de risco do estudante para a sua permanência na universidade.

O bolsista permanência deve cumprir o seu Plano de Atividades, encaminhar ao DACE, semestralmente, avaliação das atividades desenvolvidas no setor e o histórico escolar; mensalmente, a folha de frequência assinada e carimbada pelo supervisor, sendo que a não apresentação dessa folha por três meses consecutivos poderá implicar no desligamento do bolsista. O bolsista deve ainda participar das reuniões do DACE quando convocado; informar a data de sua conclusão de curso com, pelo menos, trinta dias de antecedência e informar, imediatamente, trancamento de período ou abandono de curso.

Os estudantes contemplados com a Bolsa Permanência têm o direito de escolher o Plano de Atividades e o respectivo setor no qual cumprirão a carga horária de 12 horas semanais, assim como podem migrar para outro setor, mediante análise do DACE. Têm ainda direito a recesso de 30 dias, preferencialmente no mês de janeiro. 
Os bolsistas que não obtiverem resultados satisfatórios nas avaliações de desempenho, em qualquer etapa do desenvolvimento do seu Plano de Atividades, poderão ter sua bolsa suspensa, ou serem substituídos no decorrer do período.

Em 2006, a UNIRIO iniciou a Política de Bolsa Permanência concedendo 50 bolsas no valor de $\mathrm{R} \$ 180,00$ representando, naquele ano, uma despesa anual de R\$ 99.000,00. No ano de 2010, a UNIRIO (2010b) instituiu o AuxílioAlimentação para estudantes em situação de vulnerabilidade social, sendo que todos os bolsistas permanência passaram a fazer jus ao referido auxílio de forma cumulativa com a bolsa recebida.

Ao longo dos anos, a concessão da Bolsa Permanência foi sendo ampliada em quantitativo e valor. Em 2010, a UNIRIO concedeu 300 Bolsas Permanência no valor de $\mathrm{R} \$ 360,00$ acrescida do valor de $\mathrm{R} \$ 132,00$ referente ao AuxílioAlimentação, representando um aumento de $500 \%$ no quantitativo de Bolsa Permanência oferecido pela universidade, e de $1482 \%$ de acréscimo nos valores empregados nesta política de assistência estudantil.

\section{Planejando e Desenvolvendo o Estudo}

O planejamento de uma avaliação deve ter como base a compreensão do que é uma boa avaliação. Um bom planejamento deve levar em consideração de que forma a avaliação afetará o objeto avaliado (VIANNA, 2000). Deve também levar em consideração os valores, as preocupações e as percepções dos interessados em relação ao objeto da avaliação. Somente desta forma cumpre seu papel como facilitadora de um processo de fortalecimento do seu objeto de atenção e intervém, reforçando potencialidades e sucessos, em vez de meramente registrar dificuldades e fracassos (PENNA FIRME, [2001]).

Uma avaliação, de acordo com VIANNA (2000), deve levar a conclusões que expressam as diferentes expectativas em relação às decisões a serem tomadas. A avaliação é um desafio onde a criatividade e a sensibilidade, a objetividade e a subjetividade estão presentes e atuantes, sempre que necessário, para responder com propriedade às indagações e facilitar a ação de aperfeiçoamento (PENNA FIRME, [2001]). Assim, o planejamento de uma avaliação deve ter flexibilidade suficiente para atender à diversidade de interesses e expectativas (VIANNA, 2000). 
Um fator crucial, e que está presente neste momento atual de avanços na avaliação, é o respeito à participação efetiva de todos os interessados no processo, ou stakeholders, e que, independente de sua condição social, econômica, acadêmica ou outras, são elementos essenciais que devem atuar no processo, desde sua concepção até seus resultados. Somente assim, a avaliação será útil nas necessárias transformações que os programas e projetos sociais, educacionais e culturais pretendem alcançar (PENNA FIRME, [2001]).

Neste contexto, a avaliação foi realizada considerando a visão (a) da equipe responsável pelo gerenciamento do programa na UNIRIO e (b) dos estudantes contemplados com a Bolsa Permanência, e foi norteada por duas questões avaliativas. São elas:

1) As atividades desenvolvidas pelos estudantes bolsistas contribuem para a melhoria do seu desempenho acadêmico?

2) A Bolsa Permanência contribui para a permanência do estudante bolsista na universidade?

Considerando que a avaliação deve estabelecer um diálogo enriquecedor, o estudo foi realizado de acordo com uma abordagem responsiva (STAKE, 1972 apud WORTHEN; SANDERS; FITZPATRICK, 2004).

A avaliação responsiva mostrou-se necessária uma vez que o aprofundamento do conhecimento de todos os elementos da cultura institucional é essencial para a compreensão da política de Bolsa Permanência avaliada. É necessário, também, levar em consideração que a eficiência de uma política que tem por objetivo promover a inserção de alunos de graduação, oriundos de segmentos sócioeconômicos menos favorecidos, em atividades que visem à participação plena na vida universitária, tendo como pressuposto a igualdade de oportunidades de permanência com vistas à qualidade da formação acadêmica, não pode ser medida de forma ortodoxa, por meio de instrumentos psicométricos, e com o emprego de estatísticas, por mais sofisticadas que possam ser (VIANNA, 2000). É importante ter em mente que a Instituição tem suas dúvidas, interrogações e, possivelmente, suas inquietações que deverão ser consideradas. Assim, o estudo pretende apresentar informações úteis para a melhoria do programa (WORTHEN; SANDERS; FITZPATRICK, 2004), contribuindo para o fortalecimento de seus pontos positivos e, se for o caso, promover modificações (VIANNA, 2000). 
De acordo com Worthen, Sanders e Fitzpatrick (2004, p. 302), "a avaliação deve identificar e se comunicar com todos os seus públicos para descobrir pontos de vista e preocupações com o programa e com a própria avaliação". Além disso, "o conjunto de pontos de vista dos vários públicos da avaliação ajuda a focar e direcionar o estudo" (WORTHEN; SANDERS; FITZPATRICK, 2004, p. 305). Assim, foram considerados três públicos: (a) a administração da universidade, representada pela equipe do Departamento de Assuntos Comunitários e Estudantis (DACE); (b) os profissionais docentes e técnico-administrativos que supervisionam as atividades desenvolvidas pelos estudantes bolsistas, e (c) os estudantes contemplados com a Bolsa Permanência.

Neste processo avaliativo foram utilizados dois roteiros de reunião, um questionário, um roteiro de entrevista e um roteiro de grupo focal elaborados pelo autor do estudo.

Os roteiros de reuniões possibilitam registrar questões, impressões, esperanças e temores dos interessados no estudo avaliativo, considerando que essas informações são primordiais para determinar o foco da avaliação (WORTHEN; SANDERS; FITZPATRICK, 2004).

O primeiro roteiro de reunião foi elaborado para a direção do DACE, setor responsável pelo gerenciamento da Política de Bolsa Permanência na UNIRIO. Por meio desse instrumento, pretendeu-se sensibilizar a direção e sua equipe para a avaliação realizada, obter acesso aos registros por ventura existentes sobre o desenvolvimento da Bolsa Permanência e estabelecer uma relação entre o autor e a equipe do DACE, de modo a permitir que aqueles que conduzem a ação avaliada tenham seus valores refletidos no estudo. $\mathrm{O}$ roteiro abordou questões sobre a importância da avaliação, a existência de normatização da política de Bolsa Permanência, a existência de registros sobre os estudantes contemplados com a bolsa, as necessidades que a bolsa avaliada deve atender e os possíveis problemas que pretende corrigir.

O segundo roteiro de reunião destinado aos profissionais docentes e técnicoadministrativos e estudantes envolvidos com a política de Bolsa Permanência visava sensibilizá-los para a avaliação realizada e identificar os aspectos que consideram relevantes na realização do estudo. Desta forma, buscava-se refletir na avaliação as perspectivas dos interessados. 
O questionário, contendo questões fechadas, semiabertas e abertas, foi destinado aos estudantes bolsistas. O roteiro de entrevista foi construído para o DACE e o roteiro de grupo focal para os bolsistas. Todos os três instrumentos tinham a finalidade de avaliar a adequação da política em questão abordando aspectos relacionados com as atividades realizadas pelos estudantes e a identificação de aspectos positivos e negativos por ventura existentes.

A utilização de questionário é recomendada por permitir a coleta de dados com um número maior de participantes. Já a realização da entrevista propicia esclarecimentos e obtenção de informações com maior nível de profundidade. No mesmo sentido, a realização de um grupo focal com os estudantes bolsistas permite o diálogo entre os participantes (WORTHEN; SANDERS; FITZPATRICK, 2004). Desta forma, pretendeu-se o envolvimento e aprofundamento para avaliar o objeto do presente estudo.

Os roteiros de reunião foram submetidos à validação por dois especialistas em construção de instrumentos. Os demais instrumentos foram validados por dois especialistas em construção de instrumentos e um representante do Departamento de Assuntos Comunitários e Estudantis da UNIRIO. As sugestões apresentadas foram incorporadas aos instrumentos, por exemplo, a inclusão de questões semiabertas no questionário.

Após a validação, foi realizado um pré-teste dos instrumentos com um representante do DACE e um estudante contemplado com a Bolsa Permanência, selecionados por conveniência. A seleção por conveniência mostrou-se adequada pela facilidade de acesso aos sujeitos envolvidos com a avaliação (WORTHEN; SANDERS; FITZPATRICK, 2004) e não se mostrou prejudicial, uma vez que o estudo foi realizado apenas no âmbito da UNIRIO.

Por ocasião do pré-teste foi solicitada autorização por meio de assinatura em Termo de Consentimento Livre e Esclarecido guardado em separado, com o objetivo de garantir o anonimato dos participantes.

O presente estudo foi realizado considerando as dimensões e indicadores apresentados no Quadro 1. Foram identificados dois elementos fundamentais, nomeados aqui de dimensões, que merecem ser observados na reflexão sobre a qualidade da Bolsa Permanência e sobre os quais foi possível emitir juízo 
de valor (CONSELHO ESTADUAL DE EDUCAÇÃO, 2011). Para avaliar essas dimensões, foram definidos indicadores entendidos como sinalizadores de qualidade (BRASIL, 2009).

As dimensões e os indicadores levaram em conta que as tarefas desenvolvidas pelos bolsistas, constantes dos Planos de Atividades, devem contribuir para melhoria de seu desempenho acadêmico; e a bolsa avaliada deve, na percepção dos respondentes, contribuir para a permanência do estudante na universidade e sua continuidade no curso de graduação.

Por intermédio do padrão de respostas positivas ou negativas em relação aos itens dos instrumentos, procurou-se apreciar alguns aspectos que evidenciam, na visão dos sujeitos da avaliação, a presença, ainda que parcial, ou a ausência dos indicadores utilizados.

Quadro 1 - Dimensões e indicadores para avaliação da Bolsa Permanência

\begin{tabular}{|l|l|l|}
\hline $\begin{array}{l}\text { Questão } \\
\text { Avaliativa }\end{array}$ & Dimensões & Indicadores \\
\hline 1 & $\begin{array}{l}\text { Contribuição para melhoria do } \\
\text { desempenho acadêmico }\end{array}$ & $\begin{array}{l}\text { Incentivo ao desenvolvimento acadê- } \\
\text { mico } \\
\text { Compatibilidade com a formação aca- } \\
\text { dêmica }\end{array}$ \\
\hline 2 & $\begin{array}{l}\text { Contribuição para permanên- } \\
\text { cia na universidade }\end{array}$ & Continuidade no curso \\
\hline
\end{tabular}

Fonte: O autor (2011).

A aplicação dos instrumentos foi realizada pelo autor do estudo avaliativo seguindo os padrões de direitos e interações humanas de modo a respeitar e proteger os direitos e o bem estar dos sujeitos envolvidos (JOINT COMMITTEE..., 1994).

As reuniões, que constituíram a fase divergente do estudo, foram conduzidas no período de janeiro e fevereiro de 2011 com quatro profissionais e dois estudantes envolvidos com a Política de Bolsa Permanência.

Em maio de 2011, foi realizada a entrevista com um representante do DACE. Nesta ocasião, foi solicitada assinatura em Termo de Consentimento Livre e Esclarecido, guardado em separado com o objetivo de garantir o anonimato do participante. 
Durante a realização da entrevista, as anotações foram registradas pelo entrevistador, autor do estudo, que, ao término de cada questão, relatou ao entrevistado os apontamentos para confirmar a correta compreensão das informações e, assim, conferir consistência aos dados obtidos.

Para aplicação do questionário, foram convidados a participar do estudo 288 estudantes contemplados com a Bolsa Permanência em maio de 2011. A opção por convidar a totalidade dos bolsistas mostrou-se adequada de modo a permitir ampla oportunidade de participação, o que não seria possível caso fosse selecionada apenas uma amostra dos estudantes. Para tanto, em 20 de maio de 2011, o DACE contatou os bolsistas por e-mail apresentando o autor do estudo, o objetivo da avaliação em desenvolvimento e informando que a participação era voluntária e anônima.

Com o objetivo de evitar interpretações, por parte dos estudantes, quanto ao uso inadequado dos e-mails de contato disponíveis no DACE, foi oportunizada a possibilidade de manifestar o desejo de não participar do estudo em desenvolvimento. Assim, foi indicado o prazo de três dias, até 23 de maio de 2011, para resposta ao $e$-mail; cinco estudantes informaram não desejar participar.

Em seguida o questionário foi encaminhado, via e-mail, em 25 de maio de 2011, para 283 estudantes bolsistas dos cursos de Administração, Arquivologia, Biblioteconomia, Biologia, Biomedicina, Ciências Biológicas, Ciência Política, Cenografia, Direito, Enfermagem, Filosofia, História, Interpretação, Letras, Matemática, Medicina, Museologia, Música, Nutrição, Pedagogia, Serviço Social, Sistema de Informação, Teatro/Artes Cênicas e Turismo. Na ocasião, o autor solicitou a colaboração dos estudantes bolsistas e reforçou que a participação era voluntária e anônima. Foi solicitada devolução, também por e-mail, até o dia 5 de junho de 2011. Em 31 de maio de 2011, foi encaminhado um novo e-mail agradecendo a colaboração daqueles que responderam ao questionário, e reiterando a importância da colaboração dos demais bolsistas.

$\mathrm{Na}$ metodologia do estudo foi prevista a realização de um Grupo Focal com os estudantes bolsistas. Para tanto, foi solicitada, pelo autor do estudo, a utilização da sala da Comissão Própria de Avaliação (CPA) da UNIRIO, por ser considerado um espaço apropriado para realização do encontro e com o objetivo de contribuir para o fortalecimento da cultura avaliativa na universidade. O evento contaria com a colaboração de um mestre em avaliação e um servidor técnico-administrativo, também aluno da UNIRIO, para auxiliar nas anotações. 
A primeira tentativa foi marcada para 26 de maio de 2011 e foram convidados, por e-mail, sete estudantes bolsistas dos cursos de Biblioteconomia, Enfermagem, História, Medicina, Museologia, Música e Nutrição, selecionados aleatoriamente pela relação de contatos fornecida pelo DACE, de modo a preservar a visão das diversas áreas de ensino. Nenhum dos convidados confirmou presença.

Já na segunda tentativa, prevista para ser realizada em 2 de junho de 2011, foram convidados 21 estudantes bolsistas dos cursos de Administração, Arquivologia, Biblioteconomia, Cenografia, Enfermagem, Filosofia, História, Interpretação, Medicina, Museologia, Música, Nutrição e Teatro/Artes Cênicas, quando apenas um estudante confirmou presença.

$\mathrm{Na}$ terceira e última tentativa, marcada para 10 de junho de 2011, todos os 283 bolsistas foram convidados por e-mail. Apenas um confirmou presença e cinco informaram que não poderiam participar. Assim, não foi possível realizar o encontro sem, contudo, prejudicar os resultados do estudo, uma vez que o roteiro do Grupo Focal e o questionário utilizado na coleta têm o mesmo conteúdo. Entretanto, a falta de comparecimento merece ser estudada noutra oportunidade.

Os dados coletados foram tratados qualitativa ou quantitativamente, de acordo com a especificidade dos itens dos instrumentos de coleta.

Para análise dos dados foi utilizada Estatística Descritiva, envolvendo a elaboração de gráficos, tabelas e quadros.

As questões semiabertas e abertas do questionário foram organizadas de modo a permitir o exame de coerência dos resultados (WORTHEN; SANDERS; FITZPATRICK, 2004), identificando convergências e possíveis divergências entre a visão dos estudantes bolsistas e a visão proposta pela administração da universidade conforme entrevistas realizadas com o DACE.

\section{Resultados}

Neste capítulo são apresentados os resultados relacionados com a opinião dos bolsistas, a visão da Universidade e as conclusões e recomendações do estudo. 


\section{1 a opinião dos bolsistas}

Foram recebidos 71 questionários considerados válidos. Todos os respondentes já receberam Bolsa Permanência concedida pela UNIRIO e apenas quatro não recebiam a bolsa por ocasião da coleta dos dados. Mais da metade (42) recebeu a referida bolsa no período entre um e 12 meses e estuda em horário integral (42). Quatro respondentes informaram receber a bolsa por mais de 24 meses, e este aspecto será tratado nas recomendações do estudo.

Foram convidados a participar do estudo bolsistas matriculados em 24 diferentes cursos de graduação e participaram estudantes de 19 cursos, sendo que a maior concentração ocorreu na Faculdade de Biblioteconomia (22) seguida de Enfermagem (9), Nutrição (8), Medicina (5) e Ciências Biológicas (5). Praticamente, a totalidade (60) desenvolvia as $12 \mathrm{~h}$ de atividades em área acadêmica nos diversos turnos de funcionamento da universidade, principalmente à tarde (35) e cumpre com as horas semanais de atividades (57). Apenas sete bolsistas informaram desconhecer o Plano de Atividades que deviam desenvolver, e 10 relataram que o referido plano não era respeitado.

O estudo revelou que 47 respondentes percebiam a existência de ações específicas para estimular o bom desempenho acadêmico dos bolsistas no local onde desenvolviam suas atividades, porém 22 responderam "não" à pergunta. Dentre os 11 respondentes que informaram desenvolver suas atividades em área administrativa, apenas três relataram observar a existência de ações que estimulavam seu desempenho.

Dos relatos apresentados pelos bolsistas sobre as ações desenvolvidas para estimulo de seu desempenho acadêmico no local onde desenvolviam suas atividades, o aspecto mais relevante está relacionado com a oportunidade de praticar os ensinamentos teóricos. Também foram apresentados relatos que mostram a vivência oportunizada pelas atividades. A dedicação do supervisor na sua relação com o estudante bolsista é um importante aspecto apresentado.

A questão seguinte indagou se os bolsistas elaboravam o relatório de avaliação em relação às horas de atividades desenvolvidas. Dos resultados apresentados, foi possível perceber que apenas 16 responderam "sim" à questão. Entretanto, o conteúdo do relatório apresentado pelos bolsistas indica, aparentemente, que os 
mesmos foram elaborados por solicitação do supervisor, setor ou curso, e não para o acompanhamento da política de Bolsa Permanência propriamente dita.

O estudo revelou que 50 respondentes não elaboravam relatório anual contendo a contribuição em relação ao setor em que atuou como bolsista. Entretanto, é necessário observar que 42 respondentes informaram receber a bolsa no período entre um e 12 meses; o que pode justificar a quantidade de estudantes que não elaboraram esse tipo de relatório.

Praticamente a totalidade dos respondentes (66), informou que as atividades desenvolvidas contribuíram para a formação acadêmica dos bolsistas, ainda que parcialmente (9). Apenas cinco estudantes responderam "não" à questão.

Dentre os principais aspectos relatados pelos respondentes em relação às contribuições que as atividades desenvolvidas propiciam para a formação acadêmica dos bolsistas, o mais relevante está relacionado com a possibilidade de praticar os ensinamentos adquiridos de maneira teórica. A vivência profissional, que prepara o estudante para o mercado de trabalho, foi lembrada por 15 respondentes. Foram observados relatos sobre a participação em projetos de pesquisa, a contribuição para elaboração da monografia de conclusão de curso, a possibilidade de atuarem como monitores e a aproximação entre professores e alunos que fortalece o espírito de equipe. Alguns dos respondentes (5) afirmaram que as atividades não contribuíram para sua formação por tratarem de tarefas de cunho administrativo.

A questão seguinte indagou se as 12 horas de atividades desenvolvidas pelos bolsistas interferiam com suas atividades acadêmicas. A forma como a pergunta foi formulada se mostrou pouco adequada e suscitou dúvidas por parte de seis respondentes em relação à palavra "interferência". Entretanto, como as respostas foram acompanhadas de justificativas, foi possível analisá-las considerando a existência ou não de interferência negativa. Assim, observa-se que 30 bolsistas afirmaram que as atividades realizadas interferiam negativamente, e 40 informaram que não havia interferência negativa com seus compromissos. $\mathrm{O}$ aspecto mais relevante sobre a interferência negativa no cumprimento das 12 horas semanais de atividades está relacionado com a redução de tempo para que os bolsistas possam se dedicar aos estudos. Também foram observados relatos sobre redução da grade curricular e a necessidade de faltar aulas; e esses aspectos serão tratados nas recomendações do estudo. 
Em relação a não interferência negativa, foi possível perceber que a maior parte dos relatos apresentados pelos bolsistas indica que não há incompatibilidade entre as 12 horas semanais de atividades e os compromissos acadêmicos dos estudantes. Outro aspecto que merece destaque foi o aprendizado prático oportunizado na realização das atividades.

Praticamente a totalidade dos bolsistas (57) cumpria com as 12 horas semanais de atividades, e 13 estudantes informaram não cumprir as horas. Aparentemente, o principal motivo para não cumprimento das horas está relacionado com características específicas do setor ou projeto onde o bolsista atua, bem como a sobrecarga de horários para alunos matriculados em cursos de turno integral.

A questão seguinte procurou verificar se o bolsista deve prestar horas semanais de atividades à UNIRIO em função de receber uma Bolsa Permanência. Dos resultados apresentados foi possível observar uma situação de equilíbrio entre aqueles que concordam (37) e discordam (34) quanto à obrigatoriedade de prestar horas de atividades.

Os respondentes que entendem que o bolsista deve prestar horas semanais de atividades à UNIRIO em função de receber uma Bolsa Permanência apontam, como aspecto mais relevante, o enriquecimento pessoal e profissional que o desenvolvimento dessas atividades propicia. Também se mostra relevante a visão de que é um retorno ou retribuição que o estudante pode dar à universidade em função do auxílio financeiro recebido.

As razões apresentadas pelos estudantes que discordam com o desenvolvimento das atividades estão relacionadas com a percepção de que o auxílio financeiro é uma obrigação do Governo e da universidade, portanto, é um direito do estudante, razão pela qual não deve ser exigida qualquer contrapartida. Alguns respondentes se manifestaram de forma muito contundente a esse respeito. Foram observados relatos que demonstram que o estudante entende as horas de atividades como horas de trabalho e, desta forma, discordam de ter que trabalhar para a universidade.

Em vista dos argumentos apresentados pelos bolsistas em relação à incompatibilidade de prestar horas de atividades em função do estudante frequentar curso de horário integral, foi realizada análise que permitiu perceber que, dentre os 
42 respondentes que informaram estudar em turno integral, apenas 15 discordam sobre o cumprimento das 12 horas de atividades, indicando que o fato do bolsista estudar em horário integral, aparentemente, não se mostra relevante.

Praticamente a totalidade dos respondentes (62) entende que a bolsa contribui para a sua permanência na universidade; e 9 entendem que a contribuição existe, ainda que parcialmente. Todos os relatos indicam que o principal aspecto está relacionado com o auxílio financeiro que a bolsa propicia.

$\mathrm{O}$ aspecto positivo da Bolsa Permanência mais relevante está relacionado com o auxílio financeiro propriamente dito e a contribuição geral para permanência do estudante na universidade. Outro aspecto relevante está relacionado com a experiência adquirida com o desenvolvimento das 12 horas de atividades. A atuação positiva do DACE e a liberdade de escolha das atividades que os bolsistas devem desenvolver foram apontadas por alguns respondentes.

Os aspectos negativos mais relevantes estão relacionados com a obrigatoriedade quanto ao cumprimento das 12 horas de atividades. $\mathrm{O}$ atraso no pagamento da bolsa foi lembrado por 14 bolsistas e o baixo valor do auxílio, por 11 respondentes. Quanto ao atraso no pagamento, alguns respondentes apresentaram seu descontentamento de forma bastante contundente. Foram apresentados relatos, com menor frequência, sobre a impossibilidade de acumular a bolsa com outra atividade remunerada, a impossibilidade de renovação da bolsa por período superior a 24 meses e os procedimentos burocráticos para obtenção do auxílio. Foi observado um relato sobre a existência de estudantes que recebem a Bolsa Permanência sem se enquadrar no perfil de risco social para sua manutenção na universidade e um relato sobre estudantes que não cumprem com as horas de atividades sendo que esses aspectos são abordados nas recomendações do estudo. É importante destacar que 12 respondentes informaram não observar aspectos negativos em relação à bolsa avaliada.

\subsection{A Visão da Universidade}

Foi realizada uma entrevista com a direção do DACE, e os dados coletados na entrevista pré-teste foram aproveitados devido à qualidade das informações obtidas. As respostas são descritas a seguir obedecendo à ordem das perguntas apresentadas no roteiro de entrevista. 
Na visão do DACE, os estudantes bolsistas têm conhecimento do Plano de Atividades que devem desenvolver em suas 12 horas semanais de atividades uma vez que, quando o bolsista é selecionado, os planos existentes são apresentados para escolha e os próprios bolsistas levam o formulário para o supervisor. Assim, a escolha é mútua entre bolsista e supervisor.

Quanto ao cumprimento do Plano de Atividades, o DACE recebe poucas reclamações a esse respeito. São realizadas reuniões coletivas com os bolsistas, e essa questão não aparece com frequência. Os bolsistas são orientados a procurar o DACE sempre que necessário e podem escolher outra atividade, inclusive se ocorrer mudança de interesse.

A existência, no local onde os bolsistas realizam suas atividades, de ações específicas desenvolvidas com o objetivo de estimular o bom desempenho acadêmico dos estudantes pode ser verificada pela quantidade de bolsistas que migram para as Bolsas de Monitoria, Iniciação Científica e Extensão, demonstrando o despertar para se qualificar que é, na verdade, o desejado pela universidade. Entretanto, esse é um aspecto que necessita sempre ser melhorado, por intermédio de reuniões com os supervisores, para fortalecer a visão da Política de Bolsa Permanência proposta pela UNIRIO.

O DACE não vem solicitando a apresentação de relatórios de avaliação em relação às 12 horas de atividades desenvolvidas pelos bolsistas por considerar que a frequência mensal é suficiente para acompanhar se os bolsistas estão desenvolvendo as atividades. Entretanto, essa exigência não foi retirada do Edital que rege a Bolsa Permanência para que o relatório de avaliação possa ser solicitado se, em algum momento, for considerado necessário. Existe um projeto, por exemplo, que conta com a colaboração de nove bolsistas. Neste caso, solicitar relatórios produzidos com a colaboração do supervisor representa um acréscimo de tarefas. Existe uma relação de confiança entre o DACE, os bolsistas e os supervisores. Não há fiscalização, mas acompanhamento. Pelos mesmos motivos não são solicitados relatórios anuais contendo a análise das contribuições em relação ao setor ou projeto onde o estudante bolsista atuou.

As atividades desenvolvidas pelos bolsistas contribuem para a formação acadêmica dos mesmos. É importante lembrar que a universidade não é um órgão de assistência e não promove práticas de transferência de renda. $\mathrm{O}$ 
investimento financeiro é necessário para garantir a formação dos estudantes. A maior desigualdade é a do acesso à cultura e ao conhecimento. Ainda na visão do DACE, é necessário refletir se as 12 horas de atividades representam horas que o estudante deixa de se dedicar ao curso. As atividades puramente burocráticas e administrativas não contribuem para a formação. Entretanto, o número de estudantes envolvidos em atividades administrativas é cada vez menor. As demais bolsas acadêmicas ofertadas pela universidade (exemplo: Iniciação Científica), são concedidas por mérito apurado pelo CR (coeficiente de rendimento) do estudante. É observado que o bolsista permanência, por vezes, traz consigo um déficit histórico. A igualdade de oportunidades se dá pela possibilidade de incluir o bolsista permanência nos projetos aos quais, de outra forma, não teria acesso ou seria de acesso mais difícil, principalmente, para os ingressantes. Assim, as ações de assistência têm por objetivo oportunizar a formação acadêmica dos estudantes.

As atividades realizadas pelos bolsistas interferem positivamente em suas atividades acadêmicas. A questão sobre as horas de atividades não é questionada quando se fala em outras bolsas, tais como Monitoria e Iniciação Científica. É a atividade realizada que oportuniza a vivência acadêmica, propicia contato com conhecimentos que complementam a formação e a bolsa contribui para que o estudante possa se dedicar totalmente à universidade.

O DACE espera que os bolsistas cumpram com as 12 horas de atividades, por entender que essas horas contribuem para a formação acadêmica dos mesmos. O bolsista permanência deve prestar 12 horas de atividades à UNIRIO em função de receber a Bolsa Permanência, uma vez que essas atividades propiciam contatos com conhecimentos em diversas áreas que complementam a formação do estudante e ampliam a vivência acadêmica.

A Bolsa Permanência contribui para a permanência do estudante na universidade. Existe uma linha tênue entre assistência e assistencialismo. O critério socioeconômico não é desprovido de mérito, pois o estudante ingressou na universidade. O critério socioeconômico apenas considera outros componentes. As ações de assistência estudantil desenvolvidas pela UNIRIO, inclusive a Bolsa Permanência, não contemplam todas as necessidades do estudante, entretanto, a universidade desenvolve um conjunto de ações com o objetivo de minimizar os efeitos das desigualdades sociais e socioeconômicas e, com isso, pretende atingir sua missão, que é a formação com qualidade e com compromisso social. 
O DACE destaca que o principal aspecto positivo da Bolsa Permanência está relacionado com o fato de oportunizar ao bolsista a possibilidade de vivenciar os pilares da universidade que são o ensino, a pesquisa e a extensão. É também uma possibilidade de transformação social para os estudantes.

Como principal aspecto negativo destaca as limitações físicas de espaço e a existência de poucos profissionais no DACE para desenvolver as ações de assistência estudantil em vista do acréscimo de estudantes e de auxílios concedidos pela UNIRIO. A UNIRIO concede 300 Bolsas Permanência, 600 auxílios alimentação e, em 2011, passou a conceder auxílio moradia para estudantes. Também desenvolve as ações do transporte intercampi e do Serviço de Atenção Psicossocial, dentre outras. Para desenvolver esse conjunto de ações o DACE conta com um Assistente Social responsável pela análise socioeconômica dos estudantes, um Psicólogo, três Nutricionistas, um Pedagogo, um Assistente em Administração e um Dirigente do Departamento. A análise apenas documental das solicitações de auxílios e a falta de possibilidade em conversar mais com os alunos bolsistas deixam de enriquecer o processo de seleção e, no transcorrer das atividades, prejudicam um acompanhamento mais rico das ações desenvolvidas. Assim, o acompanhamento mais próximo ao estudante só ocorre quando o mesmo procura o DACE.

\subsection{Análise de Convergência e Divergência}

Foi realizada também uma análise de convergência e possíveis divergências entre a visão proposta pela administração da universidade, conforme entrevistas realizadas com o DACE, e a visão dos estudantes bolsistas que participaram do estudo respondendo ao questionário.

A análise foi realizada tendo como porto de partida as entrevistas. Assim, nas questões onde mais de 47 bolsistas (superior a 2/3 dos respondentes) apresentaram respostas no mesmo sentido que o DACE foi considerado que a visão é convergente. Nos casos onde o quantitativo de estudantes, entre 24 e 46, apresentou as mesmas respostas, foi considerado que existe uma convergência parcial. Nas questões onde menos de 1/3 dos estudantes (23) apresentou respostas no mesmo sentido que o DACE foi considerado que a visão da administração e dos bolsistas é diferente, portanto não convergem. 
Não foram observadas situações onde a visão do DACE e dos estudantes bolsistas diverge, e apenas em duas questões a visão converge parcialmente. São eles: a interferência negativa das atividades realizadas pelos bolsistas com seus compromissos acadêmicos e a obrigatoriedade de prestação de 12 horas de atividades em função de receber uma Bolsa Permanência. Assim, percebe-se que existe, por parte dos participantes, uma boa compreensão da Política de Bolsa Permanência desenvolvida pela UNIRIO. Os aspectos em que a convergência foi parcial serão tratados nas recomendações do estudo.

\subsection{Respondendo às Questões Avaliativas}

Com base nos critérios de avaliação estabelecidos, e nos resultados obtidos com a aplicação dos instrumentos, procurou-se responder às questões avaliativas do estudo.

$\mathrm{O}$ indicador que se refere à existência de incentivo ao desenvolvimento acadêmico mostra-se evidente na visão de $2 / 3$ dos respondentes (47) que percebem a presença de ações específicas para estimular o bom desempenho dos bolsistas no local onde desenvolvem suas atividades. Já o indicador referente à compatibilidade com a formação acadêmica também se faz presente considerando que 57 bolsistas informaram que as atividades contribuem para a formação dos mesmos. Os aspectos mais relevantes relatados estão relacionados com a possibilidade de praticar o que é aprendido na teoria; a vivência profissional; a inserção em projetos de pesquisa; a participação em congressos, cursos e seminários e a dedicação pessoal do supervisor. Assim, respondendo a primeira questão avaliativa, o estudo revelou que as atividades desenvolvidas pelos estudantes bolsistas contribuem para a melhoria do seu desempenho acadêmico, embora alguns ajustes sejam necessários.

Quanto ao indicador que se refere à contribuição da Política de Bolsa Permanências desenvolvida pela UNIRIO para continuidade do estudante no curso de graduação, tal se mostrou positivo de forma elevada, tendo em vista que a totalidade dos respondentes (71) informou que a bolsa contribui para a permanência do estudante na universidade. Deste total, apenas 9 informaram que a contribuição existe, ainda que em parte. $O$ principal motivo relatado pelos estudantes está relacionado com o auxílio financeiro que a bolsa propicia para manutenção do aluno na instituição, sendo este também o aspecto positivo apresentado com maior frequência. Assim, respondendo à segunda questão 
avaliativa, observa-se que, embora seja necessário preencher algumas lacunas, a bolsa objeto do presente estudo contribui para a permanência do estudante na universidade. Desta forma, considerando que o objetivo do estudo foi avaliar a adequação da Bolsa Permanência às necessidades dos estudantes da UNIRIO, os resultados encontrados sinalizam para a possibilidade de a bolsa atingir os propósitos para os quais foi criada.

\subsection{Recomendações}

Avaliar uma ação de assistência estudantil que tem por objetivo promover a inserção de alunos de graduação, oriundos de segmentos socioeconômicos menos favorecidos, em atividades que visem a participação plena na vida universitária não é tarefa simples. Assim, é necessário habilidade e, principalmente, sensibilidade para apresentar recomendações. A partir desta realidade, e considerando os fatos descritos a seguir, foram elaboradas as recomendações deste estudo avaliativo.

Dos alunos que participaram do estudo, praticamente metade (34) entende que os bolsistas não devem prestar horas semanais de atividades à UNIRIO em função de receber uma Bolsa Permanência, e 30 afirmam que essas atividades interferem negativamente com seus compromissos acadêmicos. Entretanto, praticamente a totalidade (66) entende que essas mesmas atividades contribuem, ainda que parcialmente, para a sua formação, o que pode, aparentemente, indicar um entendimento contraditório. Os aspectos mais relevantes apresentados estão relacionados à redução do tempo para se dedicar aos estudos e ao entendimento de que o auxílio financeiro é uma obrigação do Governo e da universidade. Portanto, o estudante não deveria trabalhar para a instituição. $\mathrm{O}$ fato de 42 participantes estudarem em horário integral e, deste grupo, menos da metade (15) discordar da obrigatoriedade de prestar horas de atividades, indica que o elemento turno integral não parece ser relevante para o estudante concordar ou discordar da obrigatoriedade de prestar as horas de atividades à Universidade. Todavia, os argumentos relatados pelos bolsistas são legítimos e não devem ser refutados.

A Política de Bolsa Permanência desenvolvida tem como base a premissa de que a universidade não é um órgão de assistência e não desenvolve práticas de transferência de renda. Desta forma, a igualdade de oportunidades e a participação plena na vida universitária são oportunizadas a partir das 
atividades realizadas que propiciam contatos em diversas áreas que ampliam a vivência acadêmica dos bolsistas com vistas à sua formação com qualidade e compromisso social. Neste contexto, não se mostra razoável recomendar que a UNIRIO reveja a obrigatoriedade em relação ao cumprimento das horas de atividades dos bolsistas. Contudo, o estudo revela algumas situações que se mostram preocupantes e merecem ser reavaliadas pela universidade. Assim, recomenda-se:

1) Evitar que os bolsistas desenvolvam atividades de cunho puramente administrativo, uma vez que tanto o DACE quanto os estudantes concordam que essas atividades não contribuem para a formação acadêmica.

2) Verificar as situações de bolsistas que estão reduzindo sua grade acadêmica para poder cumprir com as 12 horas de atividades semanais e analisar as situações, caso a caso.

3) Promover encontros com os supervisores para sensibilizá-los em relação à Política de Bolsa Permanência desenvolvida pela universidade de modo que os estudantes bolsistas não tenham que perder aulas em função do cumprimento das horas de atividades.

4) Reavaliar as análises socioeconômicas dos bolsistas para verificar a possível existência de estudantes contemplados com a Bolsa Permanência que não se enquadrem no perfil de risco social para recebimento da bolsa.

5) Otimizar o fluxo administrativo para pagamento dos bolsistas de modo que o depósito das bolsas seja realizado sempre em uma mesma data, uma vez que os estudantes contam com o auxílio financeiro.

6) Reavaliar o prazo máximo de dois anos para renovação da Bolsa Permanência tendo em vista que as necessidades dos estudantes podem perdurar por todo o período de conclusão do curso. Aparentemente, já existe certa flexibilidade em relação à renovação tendo em vista que quatro bolsistas participantes do estudo informaram receber a Bolsa Permanência por mais de 24 meses.

7) Retomar as ações de avaliação dos bolsistas utilizando instrumento que poderá ser encaminhado por e-mail para os estudantes e, desta forma, manter um acompanhamento frequente que permita uma atuação tempestiva caso seja percebida alguma situação que possa comprometer a qualidade da Bolsa Permanência.

8) Criar um espaço específico do DACE na página da UNIRIO na internet para divulgação das ações de assistência estudantil desenvolvidas pela 
universidade, considerando que a internet tornou-se um fenômeno de massa ímpar na sociedade contemporânea. Neste espaço, podem ser socializadas informações tais como: (a) o objetivo da Política de Bolsa Permanência e a importância do desenvolvimento das atividades; (b) critérios utilizados para seleção dos bolsistas de modo a evitar o entendimento de que existem estudantes recebendo o auxílio indevidamente.

Finalizando, embora os resultados obtidos sinalizarem para a possibilidade da Política de Bolsa Permanência atingir os propósitos para os quais foi criada acredita-se que os resultados do estudo possam ser utilizados no sentido de aprimorar as ações de assistência estudantil desenvolvidas pela UNIRIO e por outras Instituições de ensino.

\section{Referências}

BRASIL. Constituição (1988). Constituição da Republica Federativa do Brasil. Brasília, DF, 1988. Disponível em: <http://www.planalto.gov.br/ccivil_03/ Constituicao/Constituiçao.htm>. Acesso em: 27 jun. 2010.

. Decreto $\mathrm{n}^{\mathrm{o}}$ 6.096, de 24 de abril de 2007. Institui o Programa de Apoio a Planos de Reestruturação e Expansão das Universidades Federais - REUNI. Diário Oficial da União, Brasília, DF, 25 abr. 2007a. Seção 1, p. 7. Disponível em: $<$ http://www.in.gov.br/visualiza/index.jsp?data=25/04/2007\&jornal=1\&pa gina $=7 \&$ totalArquivos $=96>$. Acesso em: 28 fev. 2011.

. Decreto $\mathrm{n}^{\mathrm{o}}$ 7.234, de 19 de julho de 2010. Dispõe sobre Institui o Programa Nacional de Assistência Estudantil - PNAES. Diário Oficial da União, Brasília, DF, 20 jul. 2010. Seção 1, p. 7. Disponível em: <http://www. in.gov.br/visualiza/index.jsp?data $=20 / 07 / 2010 \&$ jornal $=1 \&$ pagina $=5 \&$ totalArq uivos $=88>$. Acesso em: 26 jul. 2010 .

. Lei ${ }^{\circ}$ 6.655, de 5 de junho de 1979. Transforma a Federação das Escolas Federais Isoladas do Estado do Rio de Janeiro - FEFIERJ em Universidade do Rio de Janeiro - UNIRIO. Legislação, Brasília, DF, 1979. Disponível em: $<$ http://www6.senado.gov.br/legislacao/ListaPublicacoes.action?id=125284>. Acesso em: 28 fev. 2011. 
BRASIL. Lei n. ${ }^{\circ} 10.172$, de 9 de janeiro de 2001. Dispõe sobre o Plano Nacional de Educação. Leis, Brasília, DF, 2001. Disponível em: <http://www.planalto. gov.br/ccivil_03/Leis/LEIS_2001/L10172.htm>. Acesso em: 27 jun. 2010.

. Ministério da Educação. Portaria Normativa no 39, de 12 dez. 2007. Institui o Programa Nacional de Assistência Estudantil - PNAES. Diário Oficial da União, Brasília, DF, 13 dez. 2007b. Seção 1, p. 39. Disponível em: $<$ http://portal.mec.gov.br/seed/arquivos/pdf/ead/port_40.pdf >. Acesso em: 11 jul. 2010.

. Ministério da Educação. Secretaria da Educação Básica. Indicadores da qualidade na educação infantil. Brasília, DF, 2009. Disponível em: $<\mathrm{http}: / /$ revistaescola.abril.uol.com.br/educacao-infantil/indicadores-EI.pdf $>$. Acesso em: 26 abr. 2011.

CASTRO, M. H. G. A Consolidação da Política de Avaliação da Educação Básica no Brasil. Revista Meta Avaliação, Rio de Janeiro, RJ, 2009. Disponível em: $<$ http://metaavaliacao.cesgranrio.org.br/index.php/metaavaliacao/article/ view/51/30>. Acesso em: 16 jan. 2012.

CONSELHO ESTADUAL DE EDUCAÇÃO (Mato Grosso, MT). Resolução Normativa $n^{0}$ 001/2011-CEE/MT. Dispõe sobre diretrizes para elaboração de Instrumentos de Avaliação a serem utilizados em processos de regulação das Instituições de Ensino Superior - IES e de seus cursos de graduação presenciais e a distância. Diário Oficial do Mato Grosso, Mato Grosso, MT, 6 abr. 2011. p. 18. Disponível em: <http://www.cee.mt.gov.br/atos\%20normativos/2011/ RESOLU\%C3\%87\%C3\%83O\%20001-2011.pdf $>$. Acesso em: 26 abr. 2011.

\section{JOINT COMMITTEE ON STANDARDS FOR EDUCATIONAL} EVALUATION. The program evaluation standards: how do assess evaluations of educational programs. Thousand Oaks, CA: Sage, 1994. Tradução para fins exclusivamente didáticos.

PENNA FIRME, T. Os avanços da avaliação no século XXI. São Paulo, [2001]. Disponível em: <http://www.cenpec.org.br/modules/editor/arquivos/c8a0633f4d01-eae6.pdf $>$. Acesso em: 10 jul. 2010. 
SANTANA, E. B. As políticas públicas de ação afirmativa na educação e sua compatibilidade com o princípio da isonomia: acesso às universidades por meio de cotas para afrodescendentes. Ensaio: Avaliação e políticas públicas em educação, Rio de Janeiro, v. 18, n. 69, p. 736-760, out./dez. 2010.

UNIRIO. Assuntos comunitários e estudantis. Rio de Janeiro, [2006a]. Disponível em: $<$ http://www.unirio.br/propg/extensao/ass_com.html $>$. Acesso em 18 jul. 2010

. Plano de desenvolvimento institucional 2006 - 2011. Rio de Janeiro, 2006b. Disponível em: <http://www.unirio.br/propd/PDI-2006-2011.pdf>. Acesso em: 28 fev. 2011.

. Projeto pedagógico institucional. Rio de Janeiro, 2006c. Disponível em: <http://www.unirio.br/propd/PPI-2006.pdf > . Acesso em: 01 mar. 2011.

. Resolução $\mathrm{n}^{\mathrm{o}} 2.651$, de 13 de dezembro de 2005. Dispõe sobre a criação da Bolsa Permanência na UNIRIO. Boletim interno. Rio de Janeiro, 2005. Disponível em: <http://www.unirio.br/Conteudo/Reitoria/docs/ PDFBoletins2005/Bol2305.pdf $>$. Acesso em: 11 jul. 2010.

. Resolução $n^{\circ} 2.713$, de 23 de fevereiro de 2006. Dispõe sobre a Política de Bolsas Acadêmicas e de Assistência Estudantil - Rede Integrada de Bolsas UNIRIO. Boletim interno. Rio de Janeiro, 2006d. Disponível em: <http://www.unirio.br/ Conteudo/Reitoria/docs/PDFBoletins2006/Bol0206.pdf>. Acesso em: 11 jul. 2010.

UNIRIO. Resolução $\mathrm{n}^{0}$ 2.714, de 23 de fevereiro de 2006. Dispõe sobre o quantitativo, a carga horária semanal, o número de parcelas/vigência e os valores mensais das Bolsas dos Programas de Bolsas de Desenvolvimento Acadêmico e de Assistência Estudantil, mantidos pela Universidade Federal do Estado do Rio de Janeiro - UNIRIO. Boletim interno. Rio de Janeiro, 2006e. Disponível em: $<$ http://www.unirio.br/Conteudo/Reitoria/docs/PDFBoletins2006/Bol2006. pdf $>$. Acesso em: 18 jul. 2010.

. Resolução $\mathrm{n}^{0} 2.715$, de 23 de fevereiro de 2006. Dispõe sobre o orçamento do exercício de 2006 da Universidade Federal do Estado do Rio de Janeiro - UNIRIO. Rio de Janeiro, 2006f. Mimeografado. 
UNIRIO. Resolução $\mathrm{n}^{0}$ 2.787, de 06 de julho de 2006. Dispõe sobre a ampliação do quantitativo, de 50 para 56 bolsas, na modalidade Permanência, do Programa de Bolsas de Assistência Estudantil, mantido pela Universidade Federal do Estado do Rio de Janeiro - UNIRIO. Boletim interno. Rio de Janeiro, 2006g. Disponível em: <http://www.unirio.br/Conteudo/Reitoria/docs/ PDFBoletins2006/Bol1306.pdf >. Acesso em: 18 jul. 2010.

. Resolução $\mathrm{n}^{\circ} 2.834$, de 09 de maio de 2007. Dispõe sobre o orçamento de 2007 da Universidade Federal do Estado do Rio de Janeiro - UNIRIO. Rio de Janeiro, 2007a. Mimeografado.

. Resolução $\mathrm{n}^{\mathrm{o}} 2.849$, de 14 de junho de 2007. Dispõe sobre o quantitativo, a carga horária semanal, o número de parcelas/vigência e os valores mensais das bolsas dos Programas de Bolsas de Desenvolvimento Acadêmico e de Assistência Estudantil, mantidos pela Universidade Federal do Estado do Rio de Janeiro - UNIRIO. Boletim interno. Rio de Janeiro, 2007b. Disponível em: <http:/www.unirio.br/Conteudo/ Reitoria/docs/PDFBoletins2007/Bol1107.pdf $>$. Acesso em: 18 jul. 2010.

- Resolução $\mathrm{n}^{\mathrm{o}} 2.907$, de 17 de dezembro de 2007. Dispõe sobre quantitativo, a carga horária semanal, o número de parcelas/vigência e os valores mensais das bolsas dos Programas de Bolsas de Desenvolvimento Acadêmico e de Assistência Estudantil, mantidos pela Universidade Federal do Estado do Rio de Janeiro - UNIRIO. Boletim interno. Rio de janeiro, 2007c. Disponível em: $<$ http://www.unirio.br/Conteudo/Reitoria/docs/PDFBoletins2007/Bol2407. pdf $>$. Acesso em: 18 jul. 2010.

. Resolução ${ }^{\circ} 2.924$, de 21 de maio de 2008. Dispõe sobre o orçamento de 2008 da Universidade Federal do Estado do Rio de Janeiro - UNIRIO, Rio de Janeiro, 2008a. Mimeografado.

UNIRIO. Resolução $\mathrm{n}^{0}$ 2.978, de 17 de dezembro de 2008. Dispõe sobre o quantitativo, a carga horária semanal, o número de parcelas/vigência e os valores mensais das bolsas do Programa de Bolsas de Desenvolvimento Acadêmico e de Assistência Estudantil, mantidos pela Universidade Federal do Estado do Rio de Janeiro - UNIRIO. Boletim interno. Rio de Janeiro, 2008b. Disponível em: $<$ http://www.unirio.br/Conteudo/Reitoria/docs/PDFBoletins2008/Bol2408. pdf>. Acesso em: 16 jul. 2010. 
UNIRIO. Resolução n ${ }^{0} 3.136$, de 07 de julho de 2009. Dispõe sobre o orçamento do exercício de 2009 da Universidade Federal do Estado do Rio de Janeiro UNIRIO. Rio de Janeiro, 2009a. Mimeografado.

. Resolução $\mathrm{n}^{0}$ 3.237, de 15 de dezembro de 2009. Dispõe sobre o quantitativo, a carga horária semanal, o número de parcelas/vigência e os valores mensais das bolsas do Programa de Bolsas de Desenvolvimento Acadêmico e de Assistência Estudantil, mantidos pela Universidade Federal do Estado do Rio de Janeiro - UNIRIO. Boletim interno. Rio de Janeiro, 2009b. Disponível em: $<$ http://www.unirio.br/Conteudo/Reitoria/docs/PDFBoletins2009/Bol2309. pdf $>$. Acesso em: 16 jul. 2010.

. Resolução $\mathrm{n}^{\circ} 3.322$, de 29 de maio de 2010. Aprova o quantitativo mensal, o número de parcelas/vigência e o valor mensal do Auxílio-Alimentação a estudantes que justifiquem esta necessidade, a ser concedido pela Universidade Federal do Estado do Rio de Janeiro - UNIRIO, com verba específica da Assistência Estudantil. Boletim interno. Rio de Janeiro, 2010a. Disponível em: $<$ http://www.unirio.br/Conteudo/Reitoria/docs/PDFBoletins2010/Bol0810. pdf>. Acesso em: 09 jun. 2011.

. Resolução $n^{0} 3.436$, de 08 de julho de 2010. Dispõe sobre o orçamento do exercício de 2010 da Universidade Federal do Estado do Rio de Janeiro UNIRIO. Rio de Janeiro, 2010b. Mimeografado.

VIANNA, H. M. Avaliação educacional: teoria, planejamento, modelos. São Paulo: IBRASA, 2000.

WORTHEN, B. R.; SANDERS, J. R.; FITZPATRICK, J. L. Avaliação de programas: concepções, práticas. São Paulo: Gente, 2004. 


\section{Evaluation of student support policy developed by Unirio: the Permanency Scholarship Project Abstract}

This study aimed to evaluate the adequacy of the Permanency Scholarship granted by Universidade Federal do Estado do Rio de Janeiro (UNIRIO) to students from disadvantaged socioeconomic segments. The study was conducted in a responsive approach since a deeper understanding of the elements of institutional culture is essential to understanding the evaluated action and intended to reflect the values and perspectives of students and professionals involved with Permanency Scholarship. Data collection was performed with the use of a questionnaire and an interview script. There were 71 obtained data from scholarship students enrolled in 19 different graduate courses, and two interviews were conducted with Department of Community and Student Affairs (DACE). The analysis of data was conducted using descriptive statistics. Examination consistency exams of the results and possible differences between scholarship students and the view proposed by the University administration were developed. The found results point to the possibility of Permanency Scholarship achieve the goals for which was created.

Keywords: Evaluation. Higher Education. Affirmative action in higher education.

\section{Evaluación de la política de apoyo al estudiante desarrollada por UNIRIO: El Proyecto de Beca Permanencia}

\section{Resumen}

El presente estudio tiene por objeto evaluar la adecuación de la Beca Permanencia concedida por La Universidad Federal del Estado de Río de Janeiro (UNIRIO) a los estudiantes de los segmentos socioeconómicos menos favorecidos, teniéndose en cuenta las especificidades de la Universidad $y$ de los estudiantes que la referida Beca contempló. El trabajo se ha desarrollado dentro de un abordaje responsivo, ya que es esencial profundizar el conocimiento de los elementos de la cultura institucional para que se pueda comprender la acción evaluada y también por la intención de reflexionar sobre los valores y las perspectivas de los estudiantes profesionales becarios. La recolección de datos se hizo a través de la utilización de un cuestionario y una guía de entrevistas. Se obtuvieron datos de 71 estudiantes becarios 
matriculados en 19 distintos cursos de Graduación y se realizaron dos entrevistas con el Departamento de Asuntos Comunitarios y Estudiantiles (DACE). El análisis de los datos se obtuvo a través de estadística descriptiva, donde se practicó examen de coherencia de los resultados identificando convergencias y posibles divergencias entre la visión de los estudiantes becarios y la visión que la administración de la Universidad propuso. Los resultados señalan la posibilidad de que la Beca Permanencia haya alcanzado los propósitos para los cuales fue creada. Al final del estudio se presentan recomendaciones con el propósito de contribuir para mejorar la Beca Permanencia desarrollada por la UNIRIO.

Palabras clave: Evaluación. Educación Superior. Acciones afirmativas en la Enseñanza Superior. 